\title{
Paperless partogram: a simple clinical tool in effective labour management
}

\author{
Shaik Reshma*, Sri Lakshmi Ambarkar \\ Department of Obstetrics and Gynecology, Kurnool Medical College, Kurnool, Andhra Pradesh, India
}

Received: 30 March 2021

Accepted: 30 April 2021

\section{*Correspondence:}

Dr. Shaik Reshma,

E-mail: reshmariyaz228@gmail.com

Copyright: (C) the author(s), publisher and licensee Medip Academy. This is an open-access article distributed under the terms of the Creative Commons Attribution Non-Commercial License, which permits unrestricted non-commercial use, distribution, and reproduction in any medium, provided the original work is properly cited.

\section{ABSTRACT}

Background: Maternal mortality is unacceptably high, about 830 women die from pregnancy or child birth related complications around the world every-day. Prolonged and obstructed labour is one of the major causes of maternal and perinatal mortality and morbidity worldwide. In developing countries like India, around 5\% of total maternal deaths are caused by prolonged and obstructed labour. The purpose of the present study is to evaluate the role of paperless partogram in management of labour, identification of abnormal labour and early intervention to prevent the maternal and perinatal morbidity. The objective of this study was to assess the role of paperless partogram in labour monitoring and decision-making in overburdened Indian labour room setup and to evaluate the outcome of the cases.

Methods: A prospective study was conducted at a tertiary care hospital, Kurnool, Andhra Pradesh, between January 2020 to March 2020. A total of 300 pregnant mothers in established labour who fulfilled the inclusion criteria, were included in the study after taking informed consent.

Results: In our study, of all the pregnant women 23 crossed the alert ETD but 16 had delivered vaginally and 2 by caesarean section before action ETD and 5 women crossed the action ETD. Among the 5 who crossed action ETD 3 delivered vaginally and 2 had cesarean section. Majority, of the women who crossed the alert and action ETDs were primigravidae.

Conclusions: From our study, it is concluded that paperless partogram was effective and user friendly in management of labour and prevention of abnormal or prolonged labour.

Keywords: Alert ETD, Action ETD, Prolonged labour, Maternal and fetal outcome

\section{INTRODUCTION}

Maternal mortality is unacceptably high, about 830 women die from pregnancy or child birth related complications around the world every-day. It was estimated that in 2017 roughly 2,95,000 women died during and following child birth. Between 2016 and 2030 as a part of sustainable development goals 3 set by United Nations target is to reduce the global maternal mortality ratio to less than 70/100000 live births. ${ }^{1}$ Almost all of these deaths occurred in low resource settings and most could have been prevented. In India, around 5\% of total maternal deaths are caused by prolonged and obstructed labour. ${ }^{2}$ Skilled care before, during and after childbirth can save the lives of mothers and newborns. Prolonged and obstructed labour is one of the major causes of maternal and perinatal mortality and morbidity worldwide.

Partogram is a cost effective and affordable health intervention for monitoring progress of labour and acts as an 'early warning system' for appropriate decision making. Partograph was originally developed by Friedman in 1954 based on his observation on labours of women in Zimbabwe, later modified by Philpott and Castle in 1972 by inclusion of alert and action lines, which forms the basis of WHO partogram. ${ }^{3,4}$ The complex WHO 
program (1994) has extensive parameters for patient monitoring and evaluation which was further modified in 2000 by eliminating the latent phase. But still it is not that popular among busiest Indian obstetricians where the doctor patient ratio is not comparable with standard WHO guidelines. The current problem is that the complete documentation of WHO partogram is notoriously low because of lack of awareness and proper training, low availability of health personnel, high patient load, lack of supervision, negative perceptions, complexity of plotting the WHO partogram. ${ }^{5}$

With the view to evolve simple user-friendly system for centers with high delivery rates and shortage of trained staff, Debdas in 2006 has developed paperless partogram which is the need of the hour for labour management. Paperless partogram is a simple, graphless, non-time consuming, simple two step calculation requiring only basic addition and reading of clock/watch.

It involves calculation of two ETDs (expected time of delivery) which predicts delivery time based on Friedman's formula of cervicometric progress of labour, alert ETD and action ETD. For each labour case, at the very first vaginal examination in active phase of labour, 2 ETDs are to be calculated mentally and written down in big bold letters in front of the case sheet. These ETDs serve as a constant alarm for all the concerned in the labour management and makes them take necessary care. ${ }^{6}$

\section{Aim}

Aim of the study was early detection of abnormal labor and timely intervention to prevent prolonged and obstructed labour.

\section{Objectives}

Objective of the study was to assess the role of paperless partogram in labour monitoring and decision-making in overburdened Indian labour room setup and to evaluate the outcome of the cases studied.

\section{METHODS}

This prospective study was conducted at a tertiary care hospital, Kurnool, Andhra Pradesh, from January 2020 to March 2020. A total of 300 pregnant mothers, irrespective of age and parity in established labour who fulfilled the inclusion criteria, were included in the study after taking informed consent.

\section{Inclusion criteria}

Inclusion criteria of the study were as follows any gravid women irrespective of age and parity in established labour with a singleton pregnancy in cephalic presentation, regardless of whether membranes are intact or ruptured. Onset of labour has to be spontaneous.
The cervix must be at least $4 \mathrm{~cm}$ or more dilated at the time of inclusion. Gestational age should be 37 completed weeks or more.

\section{Exclusion criteria}

Exclusion criteria were patients with induced labour, CPD, malpresentations, previous cesarean section, preterm labour, IUFD, fetal distress, multiple pregnancies, hypertensive disorders of pregnancy, antepartum hemorrhage, patient on epidural analgesia and presence of any other severe complications.

Before starting the study, institutional ethical committee approval was obtained. A detailed history was taken and clinical examination was done. Relevant hematological, biochemical investigations and ultrasound were performed on all study subjects.

Data was collected using a suitable predesigned proforma. Labour progression was monitored. When a patient reached the active phase i.e, $4 \mathrm{~cm}$ cervical dilatation, we calculated 2 ETDS- alert ETD and action ETD based on Friedman's rule that cervical dilation occurs at the rate of $1 \mathrm{~cm} / \mathrm{hr}$. For example, in a case cervix was found $4 \mathrm{~cm}$ dilated at $1 \mathrm{pm}$ her ETDs are alert ETD- 1 PM+6 hours $=7$ $\mathrm{PM}$ and action ETD-7 PM+4 hours= $11 \mathrm{PM}$. Both the ETDs were written in bold letters on front page of woman's case sheet. The action ETD was circled with red colour. monitoring of progress of labour was done by 'simple 3C protocol' i.e, C1- care of mother like temperature, pulse, BP, oxytocin drip or drugs; C2- care of fetus: FHR and meconium; C3- care of contraction: duration and frequency of contractions, recorded as for example $2 \mathrm{C} / 10 / 20$ at a glance clarity in-contrast to WHO partogram which uses complex designs. Abnormal findings are encircled in red for flagging at a glance alarm. ${ }^{6}$

How many PVs are to be done?

(a) After allotting the ETDs next PV to be done 3 hours after that and next one at the time of alert ETD and (b) If not delivered by alert ETD next PV to be done 3 hours after alert ETD (in contrast to WHO partogram where PV is done two hourly which causes discomfort to the patient and increases the risk of infection. ${ }^{6}$

For example, if uterine contractions are poor and close to Alert ETD, labour is augmented by arm or by oxytocics as necessary. If the delivery does not occur by Action ETD, the patient is at risk of prolonged labour and termination is planned by suitable medical or surgical intervention.

\section{RESULTS}

In our study majority of pregnant women were between age group of 21 to 25 years $(51 \%)$ with mean age of 25.23 years and multigravida accounted for $56.33 \%$. Most of the women were booked and immunized i.e., $57.6 \%$ with gestational age between $37-40$ weeks $(84 \%)$. $63 \%$ of the 
cases had cervical dilatation of $4 \mathrm{~cm}$ at the time of assigning alert and action ETD. Of all the cases 23 women crossed the alert ETD but 16 had delivered vaginally and 2 by caesarean section due to fetal distress and secondary arrest in dilatation before action ETD and 5 women crossed the action ETD. Among the 5 who crossed action ETD 3 delivered vaginally and 2 had caesarean section. Majority, of the women who crossed the alert and action ETDs were primigravidae. Augmentation of labour was done in $34.3 \%$ (Table 8 ). 17 out of 300 women underwent LSCS with indications being secondary arrest of dilatation or descent in 6 cases and fetal distress in 11 cases. Maternal complications like PPH was found in $1.6 \%$ cases. The mean birth weight of newborns was $2.91 \mathrm{Kg}$ and majority $(95.6 \%)$ of newborns were with Apgar $>7$ at 5 minutes. NICU admission was found in $5 \%$ of cases, with major indication being meconium aspiration.

Table 1: Age distribution.

\begin{tabular}{|c|c|c|}
\hline $\begin{array}{l}\text { Age group } \\
\text { (years) }\end{array}$ & $\begin{array}{l}\text { No. of } \\
\text { cases }\end{array}$ & Percentage (\%) \\
\hline 18 to 20 & 16 & 5.3 \\
\hline 21 to 25 & 154 & 51.3 \\
\hline 26 to 30 & 109 & 36.3 \\
\hline$>\mathbf{3 0}$ & 21 & 7 \\
\hline Total & 300 & 100 \\
\hline
\end{tabular}

Table 2: Parity distribution.

\begin{tabular}{|c|c|c|}
\hline Parity & $\begin{array}{l}\text { No. of } \\
\text { cases }\end{array}$ & Percentage (\%) \\
\hline Primigravida & 131 & 43.6 \\
\hline Multigravida & 169 & 56.33 \\
\hline Total & 300 & 100 \\
\hline
\end{tabular}

Table 3: Booked and unbooked cases.

\begin{tabular}{|c|c|c|}
\hline Booking & $\begin{array}{l}\text { No. of } \\
\text { cases }\end{array}$ & Percentage $(\%)$ \\
\hline Booked & 173 & 57.6 \\
\hline Unbooked & 127 & 42.3 \\
\hline Total & 300 & 100 \\
\hline
\end{tabular}

Table 4: Gestational age.

\begin{tabular}{|lll|}
\hline $\begin{array}{l}\text { Gestational age } \\
\text { (weeks) }\end{array}$ & $\begin{array}{l}\text { No. of } \\
\text { cases }\end{array}$ & Percentage $(\%)$ \\
\hline $\mathbf{3 7 - 4 0}$ & 252 & 84 \\
\hline $\mathbf{7 4 0}$ & 48 & 16 \\
\hline Total & 300 & 100 \\
\hline
\end{tabular}

Table 5: Distribution of cervical dilation.

\begin{tabular}{|lll|}
\hline $\begin{array}{l}\text { Cervical } \\
\text { dilatation }(\mathbf{c m})\end{array}$ & $\begin{array}{l}\text { No. of } \\
\text { cases }\end{array}$ & Percentage $(\boldsymbol{\%})$ \\
\hline $\mathbf{4}$ & 189 & 63 \\
\hline $\mathbf{5}$ & 88 & 29.3 \\
\hline $\mathbf{6}$ & 23 & 7.6 \\
\hline
\end{tabular}

Table 6: Distribution of parturients crossing alert ETD.

\begin{tabular}{|lll|}
\hline $\begin{array}{l}\text { Crossing alert } \\
\text { ETD }\end{array}$ & No. of cases & Percentage (\%) \\
\hline Yes & 23 & 7.60 \\
\hline No & 277 & 92 \\
\hline Total & 300 & 100 \\
\hline
\end{tabular}

Table 7: Distribution of parturients crossing alert ETD.

\begin{tabular}{|lll|}
\hline $\begin{array}{l}\text { Crossing action } \\
\text { ETD }\end{array}$ & No. of cases & Percentage (\%) \\
\hline Yes & 5 & 1.6 \\
\hline No & 295 & 98.3 \\
\hline Total & 300 & 100 \\
\hline
\end{tabular}

Table 8: Augmentation of labour.

\begin{tabular}{|lll|}
\hline Augmentation & $\begin{array}{l}\text { No. of } \\
\text { cases }\end{array}$ & Percentage (\%) \\
\hline Yes & 103 & 34.3 \\
\hline No & 197 & 65.6 \\
\hline Total & 300 & 100 \\
\hline
\end{tabular}

Table 9: Mode of Delivery.

\begin{tabular}{|l|l|}
\hline Mode of delivery & No. of cases \\
\hline Spontaneous vaginal delivery & 277 \\
\hline Forceps & 0 \\
\hline Vaccum & 6 \\
\hline LSCS & 17 \\
\hline Total & 300 \\
\hline
\end{tabular}

Table 10: Indications for LSCS.

\begin{tabular}{|l|l|}
\hline Indication & No. of cases \\
\hline $\begin{array}{l}\text { Secondary arrest of dilatation } \\
\text { and descent dilation }\end{array}$ & 6 \\
\hline Fetal distress & 11 \\
\hline Total & 17 \\
\hline
\end{tabular}

Table 11: Maternal outcome (complications).

\begin{tabular}{|l|l|l|}
\hline $\begin{array}{l}\text { Postpartum } \\
\text { hemorrhage }\end{array}$ & $\begin{array}{l}\text { No. of } \\
\text { cases }\end{array}$ & Percentage $(\%)$ \\
\hline Yes & 5 & 1.6 \\
\hline No & 295 & 98.3 \\
\hline Total & 300 & 100 \\
\hline
\end{tabular}

Table 12: Neonatal outcome.

\begin{tabular}{|lll|}
\hline Neonatal & No. of cases & Percentage $(\%)$ \\
\hline Yes & Apgar $<7$ at 5 min & 13 \\
\hline No & Apgar $>7$ at 5 min & 287 \\
\hline Total & NICU admissions & 15 \\
\hline
\end{tabular}




\section{DISCUSSION}

Though the use of partogram has been universally recommended by WHO, but still its application is limited in low resource settings. Paperless partogram proposed by Debdas's method is simple, low skilled and more acceptable in low resource settings. The present study planned to evaluate the role of paperless partogram in management of labour, identification of abnormal labour and early intervention to prevent the maternal and perinatal morbidity. In this study 300 women were enrolled, various parameters like age, parity, cervical dilatation, parturient crossing alert and action ETD, augmentation of labour, mode of delivery, maternal and neonatal outcome were studied. The observations from our study was in accordance with the studies conducted by Agarwal et al, Lingegowda et al, Kumar et al and Jain et al. ${ }^{7-10}$ In all these studies the paperless partogram was found to be user friendly, effective hand over tool when clinicians changed shifts ensuring continuous monitoring of labour.

\section{CONCLUSION}

From our study, it is concluded that paperless partogram was effective and user friendly in management of labour and prevention of abnormal or prolonged labour when compared to WHO partogram in low risk cases. Even though modified WHO partogram is simpler when compared to conventional partogram, but it is still rarely used in overburdened and busy labour rooms and at the peripheral health care centres due to lack of knowledge and awareness. So, at the peripheral health care centres where deliveries are conducted by killed birth attendants implementation of paperless partogram helps in the early identification of abnormal or prolonged labour and referral to higher centres with emergency obstetric care, decreases the maternal and perinatal morbidity and mortality associated with prolonged and obstructed labour.

Funding: No funding sources Conflict of interest: None declared

Ethical approval: The study was approved by the Institutional Ethics Committee

\section{REFERENCES}

1. UNFPA, WHO, UNICEF, World Bank Group, the United Nations Population Division. Trends in maternal mortality:2000 to 2017. 2019.

2. Pitkin RM. Friedman EA. Primigravid labor: a graphicostatistical analysis. Obstet Gynecol 1955;6:567-89.

3. Montgomery AL, Ram U, Kumar R, Jha P, Million Death Study Collaborators. Maternal mortality in India: causes and healthcare service use based on a nationally representative survey. PLoS One. 2014;9(1):83331.

4. Philpott RH, Castle WM. Cervicographs in the management of labour in primigravidae. I. The alert line for detecting abnormal labour. J Obstet Gynaecol Br Commonw. 1972;79(7):592-8.

5. Veena L, Anagondanahalli S, Suchitra P. Study to Compare between paperless partogram and modified WHO partogram in management of labour. Int $\mathbf{J}$ Reprod Contracept Obstet Gynecol. 2018;7:99-103.

6. Devdas AK. ETD - A 20 second tool for absolute prevention of prolonged and obstructed labor in resource poor situations. The New Indian Journal of OBGYN. 2015;2(1):24-6.

7. Agarwal K, Agarwal L, Agrawal VK, Agarwal A, Sharma M. Evaluation of paperless partogram as a bedside tool in the management of labor. J Family Med Prim Care. 2013;2(1):47-9.

8. Lingegowda K, Bhuvaneswari, Shailaja N, Kulkarni $\mathrm{N}$, Bhatt SB, Vimala. Comparison of WHO partograph with Paperless partograph in the management of labour and to determine which is more user friendly. AICOG Patna. 2014:106-7.

9. Giri DK, Nayak L, Dalai DK. Comparision of procedure and predictability between WHO partogram and Paperless partogram. JMSR. 2019;7:107.

10. Jain A, Rajini P, Vishwa K. Paperless PartogramBedside Tool for Effective and Vigilent Management of Labour. Natl J Integr Res Med. 2017;8(2):158-160.

Cite this article as: Reshma S, Ambarkar SL. Paperless partogram: a simple clinical tool in effective labour management. Int J Reprod Contracept Obstet Gynecol 2021;10:2308-11. 